\title{
Epidermal nuclear immunoglobulin deposits in some connective tissue diseases: correlation with ENA antibodies
}

\author{
IRENE ANDERSEN, ${ }^{1}$ PAUL ANDERSEN,${ }^{2}$ PREBEN ELLING,${ }^{3}$ AND \\ HANS GRAUDAL ${ }^{1}$ \\ From the ${ }^{1}$ Rheumatism Unit, Aarhus University Hospital, ${ }^{2}$ Institute of Medical Microbiology, University of \\ Aarhus, and ${ }^{3}$ Medical Department $P$, Randers City Hospital, Denmark
}

SUMMARY In-vivo nuclear deposits of IgG were demonstrated by direct immunofluorescence in epidermal cells of normal skin from 6 patients with serum antibodies to an RNase-sensitive extractable nuclear antigen (ENA). Addition of complement to the skin sections showed that C3 could bind to epidermal cells with IgG deposits. A skin biopsy from a patient with polymyositis and serum antibodies to ENA, but without nuclear IgG deposits, showed nuclear binding of C3 after addition of complement to the skin sections. The clinical diagnoses of patients with immunofluorescent staining of epidermal cells were mixed connective tissue disease (MCTD) 4 cases, systemic lupus erythematosus (SLE) 2 cases, and polymyositis 1 case. No epidermal nuclear IgG deposits could be demonstrated in 5 cases of SLE, 2 cases of MCTD, one case of polymyositis, or 15 cases of rheumatoid arthritis without antibodies to ENA.

Patients with combined features of systemic lupus erythematosus (SLE), scleroderma, and polymyositis and high titres of antibodies to an extractable nuclear antigen (ENA), sensitive to ribonuclease (RNase), have been described as having mixed connective tissue disease (MCTD). ${ }^{1}$ Immunofluorescence studies of skin biopsies from patients with some rheumatological diseases have shown the deposition of nuclear immunoglobulin G (IgG) in some cases, ${ }^{2-5}$ and several of these patients also had circulating antibodies to ENA. ${ }^{45}$ It is therfore possible that the epidermal nuclear IgG deposits in skin may be a feature of MCTD.

In the present study we have performed immunofluorescence studies of skin biopsies from patients with connective tissue diseases, including some with clinical characteristics of MCTD. ${ }^{6}$ We investigated whether nuclear immunoglobulin deposits correlated with a clinical diagnosis and/or the presence of antibodies to ENA in serum.

\section{Materials and methods}

PATIENTS

A group of 15 patients (14 women and one man)

Accepted for publication 5 February 1982.

Correspondence to P. Andersen, Institute of Medical Microbiology, Bartholin Building, University of Aarhus, DK-8000 Aarhus C, Denmark. aged 29-70 years, suspected from their clinical records of having MCTD, were selected by one observer (I.A.). The patients were tentatively classified by another observer (H.G.) on the basis of the course of their disease and findings prior to the present investigation. Five cases classified as MCTD had a compatible clinical picture ${ }^{6}$ and had previously had high titres of anti-ENA. One case classified as possible MCTD had previously had antinuclear antibody (ANA) of speckled type but no anti-ENA. Seven patients classified as SLE or possible SLE had mild disease and no renal involvement. Two of these had 3 or 4 of the preliminary ARA criteria for the diagnosis of SLE and positive tests for ANA. ${ }^{7}$ In the other 5, LE cells and/or significant titres of antibodies to ds-DNA, with involvement of 2 or more organ systems had previously been found, and in 2 of them 4 ARA criteria were present. The 2 remaining patients had polymyositis with typical electromyographic and pathological findings and high levels of serum creatine phosphokinase. The individual diagnoses in these 15 patients are given in Table 2. Another group of 15 patients (13 women and 2 men) aged 33-63 years, who fulfilled the ARA criteria ${ }^{8}$ for classical or definite rheumatoid arthritis (RA) were included as a control group. All patients were reexamined and agreed to have a skin biopsy taken, and a serum sample was obtained from each subject and stored at $-20^{\circ} \mathrm{C}$. 


\section{IMMUNOFLUORESCENCE STUDIES OF SKIN} BIOPSIES

Biopsies of normal skin were taken from the right forearm by punch drill, frozen immediately in liquid nitrogen, and stored at $-70^{\circ} \mathrm{C}$ in airtight vials until examination. Biopsies were serially sectioned on a cryostat. The sections, $4 \mu \mathrm{m}$ thick, were examined by direct immunofluorescence with fluorescein-isothiocyanate (FITC)-conjugated antihuman IgG, IgA, IgM, and C3 (Behringwerke AG, Germany). The molar fluorescein to protein (F:P) ratios of the conjugates were $2 \cdot 0: 3 \cdot 0$, and they were used in dilution corresponding to an antibody content of $1: 4$ units $/ \mathrm{ml}$. The anti-C3 conjugate was used at a dilution of 1:10. The conjugates did not cross-react by gel precipitation or in an indirect immunofluorescence system with ANA of different Ig classes.

Biopsy sections were washed with phosphate buf-

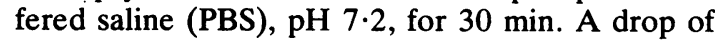
conjugate was placed on each section, and the sections were incubated in a moist chamber for $30 \mathrm{~min}$ at room temperature. The slides were then washed in PBS for $30 \mathrm{~min}$ and mounted in $50 \%$ glycerol in PBS.

A complement fixation test to investigate the ability of deposited Ig to fix complement was carried out as follows. Skin sections were washed in barbital buffer, $\mathrm{pH} 7 \cdot 4$, for $30 \mathrm{~min}$ and incubated for $30 \mathrm{~min}$ with a drop of fresh normal human serum (NHS) diluted 1:4 with barbital buffer. The slides were washed in PBS for $30 \mathrm{~min}$ and the sections incubated with a drop of antihuman $\mathrm{C} 3$ conjugate for $30 \mathrm{~min}$, then washed in PBS, and mounted in $50 \%$ glycerol. To confirm that the anti- $\mathrm{C} 3$ conjugate did not react with in-vivo bound Ig, skin sections from patients 1 , 2,5 , and 6 (Table 1 ) incubated with inactivated NHS $\left(56^{\circ} \mathrm{C}, 30 \mathrm{~min}\right)$ and with anti-C 3 conjugate were included as negative controls. The slides were read in a binocular fluorescence microscope (Carl Zeiss, W. Germany).

\section{ANTIBODY TESTS}

Autoantibodies were tested for by indirect immunofluorescence. ${ }^{9}$ Unfixed tissue sections $4 \mu \mathrm{m}$ thick of rat stomach and kidney were used as antigens. The following antibodies were recorded: antinuclear antibodies (ANA) reacting with nuclei of renal tubular cells (the staining patterns of ANA were recorded at 1:10 serum dilution); smooth-muscle antibodies (SMA) reacting with gastric smooth muscle; parietal cell antibodies (PCA) reacting with cytoplasm of gastric parietal cells; mitochondrial antibodies (MTA) reacting with cytoplasm of both renal tubular cells and gastric parietal cells; reticulin antibodies (RetA) reacting with perivascular fibres in adventitia of renal vessels; and glomerular antibodies (GA) reacting with renal glomeruli. All sera were tested in doubling dilution, starting at 1:10. The conjugates and the optical system employed were as described above. Antibodies to extractable nuclear antigens (ENA) were detected by counterimmunoelectrophoresis according to Kurata and Tan. ${ }^{10}$ Electrophoresis was carried out in an LKB apparatus in $0.05 \mathrm{M}$ barbital buffer, pH 8.6, and run for $45 \mathrm{~min}$. The antigen used was lyophilised rabbit thymus (Pel-Freeze Biological, USA) extracted overnight at $4^{\circ} \mathrm{C}$ with PBS, $\mathrm{pH} 7 \cdot 2$, and adjusted to a protein concentration of $10 \mathrm{mg} / \mathrm{ml}$. RNase treatment of antigen was as described by Kurata and $\operatorname{Tan}^{10}$ at an enzyme to substrate ratio of $1: 10$. The mixture was incubated for $30 \mathrm{~min}$ at $37^{\circ} \mathrm{C}$ and centrifuged at room temperature at $1000 \mathrm{rpm}$ for $30 \mathrm{~min}$. Positive control sera with antibody to RNase-sensitive ribonucleoprotein (RNP) and RNase-resistent antigens (Sm) were included in each electrophoretic run. The plates were read immediately and after overnight incubation in a moist chamber at room temperature.

\section{Results}

Positive immunofluorescent staining results were

Table 1 Immunoglobulin and complement deposits in skin of 9 patients with rheumatic diseases

\begin{tabular}{|c|c|c|c|c|c|c|c|c|}
\hline \multirow[t]{3}{*}{ Patient } & \multirow[t]{3}{*}{ Specimen no. } & \multicolumn{5}{|c|}{ Nuclei } & \multirow{3}{*}{$\begin{array}{l}\text { Dermoepidermal } \\
\text { - junction } \mathrm{IgG} / \mathrm{C} 3\end{array}$} & \multirow{3}{*}{$\begin{array}{l}\text { Clinical } \\
\text { diagnosis }\end{array}$} \\
\hline & & \multicolumn{4}{|l|}{$D I F$} & \multirow{2}{*}{$\frac{D I F+C}{C 3}$} & & \\
\hline & & $\operatorname{Ig} G$ & $\operatorname{IgA}$ & $I g M$ & C3 & & & \\
\hline \multirow[t]{2}{*}{1} & 1 & ++ & + & - & - & + & - & \multirow[t]{2}{*}{ MCTD } \\
\hline & 2 & + & - & - & - & ++ & - & \\
\hline 2 & 1 & ++ & - & - & - & +++ & ++ & MCTD \\
\hline 3 & 1 & + & - & - & - & +++ & - & SLE \\
\hline 4 & 1 & + & - & - & - & ++ & - & MCTD \\
\hline 5 & 1 & ++ & - & - & - & +++ & - & MCTD \\
\hline \multirow[t]{2}{*}{6} & 1 & ++ & - & - & - & +++ & + & \multirow[t]{2}{*}{ SLE } \\
\hline & 2 & + & - & - & - & ++ & - & \\
\hline 7 & 1 & - & - & - & - & $t^{1}$ & - & Polymyositis \\
\hline 8 & 1 & - & - & - & - & - & +++ & SLE \\
\hline 9 & 1 & - & - & - & - & - & ++ & SLE \\
\hline
\end{tabular}

'Not all areas of biopsy were stained.

DIF = direct immunofluorescence. 


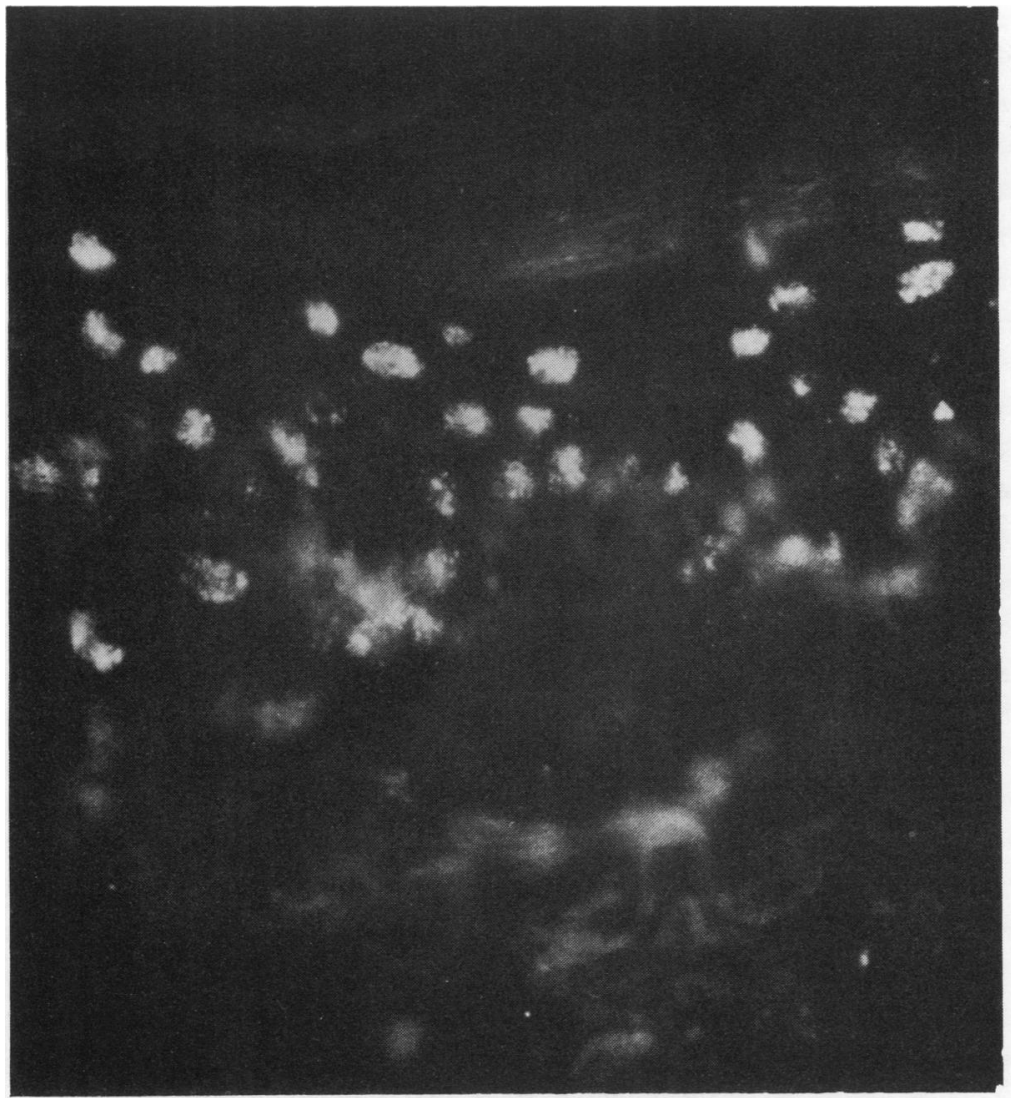

Fig. 1 Direct immunofluorescent staining for IgG in normal skin of a patient with mixed connective tissue disease. Speckled staining of epidermal nuclei is seen.

obtained with skin biopsies from the 9 patients shown in Table 1. No deposits of Ig or complement were observed in the remaining 21 patients. Nuclear IgG staining was seen in cells of the epidermis (Fig. 1) and around the hair follicles in 6 cases. Nuclear IgA deposits were noted in the epidermal cells in one patient (no. 1) who had a serum IgA ANA titre of 1280. A subsequent biopsy from the same patient 4 months later, when the serum IgA ANA titre had decreased to 320 (Table 2), showed only IgG and no IgA nuclear staining. No IgM or C3 deposits in epidermal cells were detected in any of the biopsies.

After addition of NHS to the sections as a complement source staining of $\mathrm{C} 3$ was observed in all specimens with IgG nuclear deposits, and the intensity of staining was generally stronger than with the antiIgG conjugate. One biopsy negative for IgG nuclear deposits showed a positive reaction with an anti-C3 conjugate after addition of NHS to the sections, though not all areas in the sections were stained. This biopsy was from a male patient thought to have polymyositis (no. 7), and receiving steroids at the time of investigation. Granular IgG deposits at the dermoepidermal junction were found in 4 cases, 2 (nos 2 and 6) with nuclear deposits also, and 2 patients (nos 8 and 9) with SLE, who had IgG deposits at the dermoepidermal junction only. Antibodies to ENA were detected in all 7 patients with nuclear fluorescence. In one of these patients (no. 6) ENA antibodies were found only in the first serum sample investigated and were absent 7 months later, although nuclear IgG deposits could still be demonstrated in the skin. Positive tests for ENA antibody were in all cases abolished by RNase, and were not detected in serum from patients without nuclear fluorescence of epidermal cells.

In the 6 patients with nuclear IgG deposits the tentative clinical diagnosis was MCTD in 4 and SLE in 2. However, one of the cases classified as SLE (no. 6 ) had only 3 ARA criteria, with no LE cells and no antibodies to DNA. It appears from Table 2 that the serum IgG ANA titres were generally higher in patients with nuclear fluorescence (nos 1-7) than in patients without deposits (nos 8-15). Five of the 


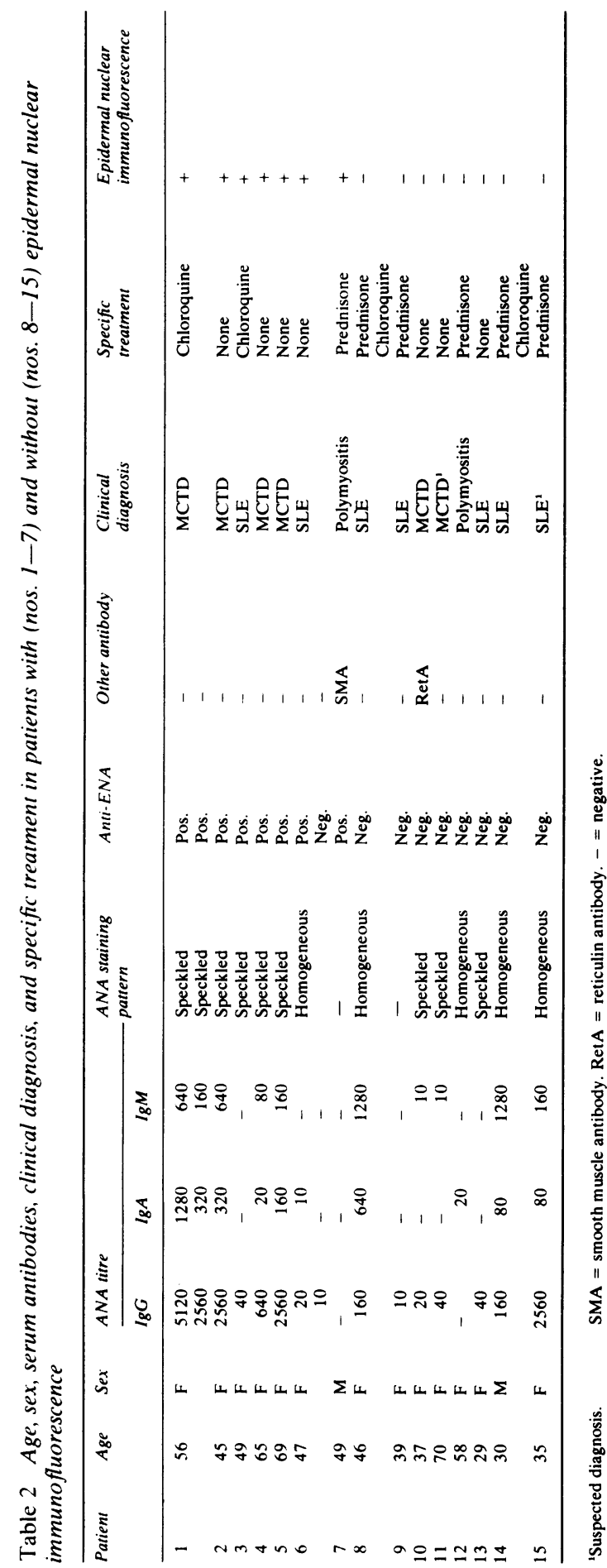

latter 8 patients were receiving steroids at the time of investigation.

ANA titres in the range 10 to 160 were found in 10 of the 15 RA patients. One RA patients had both PCA and SMA and another had RetA. ENA antibodies were not detected in the RA patients.

\section{Discussion}

Our finding of nuclear IgG deposits in clinically normal skin from patients with ENA antibodies is in agreement with other studies. ${ }^{45}$ It has previously been shown that IgG antibody to nuclear ribonucleoprotein from a patient with MCTD can penetrate in vitro viable human mononuclear cells with Fc receptors. ${ }^{11}$ It was suggested that the antibody entered the cells via the Fc receptors and then reacted with nuclear antigen in the cells. ${ }^{11}$ A similar reaction may occur in the skin in vivo since epidermal Langerhans cells bear both $\mathrm{Fc}$ and $\mathrm{C} 3$ receptors. ${ }^{12}$

It has not been possible to demonstrate deposition of $\mathrm{C} 3$ in epidermal cells in normal skin from patients with rheumatic diseases, ${ }^{45}$ which suggests that C3 cannot react in the cells in vivo. However, it was shown that $\mathrm{C} 3$ could bind to epidermal nuclei in sections where nuclear IgG deposits were present, ${ }^{5}$ which appears to indicate that nuclear IgG had participated in immune complex formation within the cells.

In one of our patients with polymyositis (no. 7) no epidermal nuclear IgG deposits could be demonstrated, but fluorescent staining of $\mathrm{C} 3$ was observed after addition of complement to the sections. This finding might be explained by the higher sensitivity of immunofluorescence when complement had been added as an additional layer. This patient was receiving steroids at the time of investigation, and had circulating antibodies to ENA. Another patient with nuclear IgG deposits in skin had both antibodies to ENA and low titres of homogeneous ANA in the serum. In a subsequent skin biopsy obtained 7 months later nuclear IgG deposits could still be demonstrated, but no circulating serum anti-ENA were now detected, and ANA was present only in very low titre. In this case speckled ANA may have been present in the serum at a concentration too low to be detected, or the antigens may have been extracted from the tissue sections during washing. An alternative explanation is that, although antibody formation had occurred, there was no free circulating antibody because all the antibody was bound to the tissues. In vivo nuclear staining in patients without detectable serum ANA was also found by Baart De La FailleKuyper. $^{3}$

In previous studies positive epidermal nuclear fluorescence has been found predominantly in 
patients with $\mathrm{SLE}^{45}$ and was reported in 9 out of 10 patients with procainamide-induced SLE. ${ }^{3}$ Two patients in the present study had granular IgG at the dermoepidermal junction in addition to the nuclear deposits, suggesting common features between MCTD and SLE. None of our RA patients showed epidermal nuclear staining, in contrast to the findings of Gilliam et al., ${ }^{4}$ who demonstrated nuclear IgG in 3 patients with RA. However, ENA antibodies have been demonstrated in patients with RA, especially in those with extra-articular disease. ${ }^{13}$ In our study epidermal nuclear IgG deposits occurred particularly in patients with high titres of speckled ANA and antibodies to RNase-sensitive ENA. One of the 7 cases with nuclear IgG described by Shu et al. ${ }^{5}$ had antibodies to $\mathrm{Sm}$ rather than RNP antigen, and we found nuclear IgG deposits in one patient without any detectable ENA antibodies. However, we have found IgG deposits in epidermal cells predominantly in patients with circulating antibodies to RNasesensitive ENA, which supports the concept that they represent a disease entity. ${ }^{1}$ It is of interest that nuclear IgG deposits are found in cells in clinically normal skin, indicating that they do not per se cause pathological lesions.

This study was supported by grants from P. Carl Petersen's fund and the Danish Medical Research Council (12-2262).

\section{References}

1 Sharp G C, Irvin W S, Tan E M, Gould R G, Holman H R. Mixed connective tissue disease-an apparently distinct rheumatic disease syndrome associated with a specific antibody to an extractable nuclear antigen (ENA). Am J Med 1972; 52: 148-59.
2 Tan E M, Kunkel H G. An immunofluorescent study of skin lesions in systemic lupus erythematosus. Arthritis Rheum 1966; 9: $37-46$

3 Baart De La Faille-Kuyper E H. In-vivo nuclear localization of immunoglobulins in clinically normal skin in systemic and procainamide-induced lupus erythematosus. Neth J Med 1974; 17: 58-65.

4 Gilliam J N, Smiley J D, Ziff M. Association of mixed connective tissue disease (MCTD) with immunoglobulin localization in epidermal nuclei of biopsies from areas of normal skin. Clin Res 1975; 23: 229A.

5 Shu S, Provost T, Croxdale M B, Reichlin M, Beutner E H. Nuclear deposits of immunoglobulins in skin of patients with systemic lupus erythematosus. Clin Exp Immunol 1977; 27: 238-44.

6 Sharp G C. Mixed connective tissue disease. Bull Rheum Dis 1974; 25: 828-31.

7 Cohen A S, Reynolds W E, Franklin E C, et al. Preliminary criteria for the classification of systemic lupus erythematosus. Bull Rheum Dis 1971; 21: 643-8.

8 Ropes M W, Bennett G A, Cobb S, Jacox R, Jessar R A. 1958 Revision of diagnostic criteria for rheumatoid arthritis. Bull Rheum Dis 1958; 9: 175-6.

9 Andersen P. Indirect immunofluorescence studies of smooth muscle antibodies. Acta Pathol Microbiol Scand (B) 1974; 82: 577-84.

10 Kurata N, Tan E M. Identification of antibodies to nuclear acidic antigens by counterimmunoelectrophoresis. Arthritis Rheum 1976; 19: 574-80.

11 Alarcon-Segovia D, Ruiz-Arguelles A, Fishbein E. Antibody to nuclear ribonucleoprotein penetrates live human mononuclear cells through Fc receptors. Nature 1978; 271: 67-9.

12 Stingl G, Wolff-Schreiner E C, Pichler W J, Gschnait F, Knapp W, Wolff K. Epidermal Langerhans cells bear Fc and C3 receptors. Nature 1977; 268: 245-6.

13 Venables P J W, Erhardt C C, Maini R N. Antibodies to extractable nuclear antigens in rheumatoid arthritis: relationship to vasculitis and circulating immune complexes. Clin Exp Immunol 1980; 39: 146-53. 